\title{
Structural Zero Data of COVID-19 Discovers Exodus Probabilities
}

\author{
Ramalingam Shanmugam (D) \\ Karan P Singh $\mathbb{D D}^{2}$
}

'School of Health Administration, Texas State University, San Marcos, TX, 78666, USA; ${ }^{2}$ Department of Epidemiology and Biostatistics, School of Community and Rural Health, The University of Texas Health Sciences Center at Tyler, Tyler, TX, 75708, USA
Correspondence: Karan P Singh Department of Epidemiology and Biostatistics, School of Community and Rural Health, The University of Texas Health Sciences Center at Tyler, Tyler, TX, 75708, USA

Email karan.singh@uthct.edu
Background: Challenges to manage, mitigate, or prevent the COVID-19's pandemics are felt by medical, healthcare professionals and governing agencies. Health researchers conduct survey among the citizens to capture their opinion on COVID-19. In such surveys like in Hanafiah and Wan (2020), structural-zero (different from sampling zero) category occurs as they question about perception, knowledge, and communication regarding COVID-19.

Materials: The data were collected in a survey conducted among Malaysians by Hanafiah and Wan regarding COVID-19. The survey focused on people's response about the public communication, knowledge, and perception.

Methods: One of the four question categories in the survey is mutually exclusive with the other three questions. Consequently, there will be no entry in that category. Such group is called structurally zero category in the literature. The literature never probed the migrative split to other categories of the unknown proportion belonging to the structural zero category. In this article, the probability-based new and innovative method configures what proportion in that mutually exclusive category and it is the essence of our method.

Results: The mutually exclusive nature of subquestions manufactured structural zero in their data. A careful analysis of the data has created so far unknown probability concepts in the literature, which we named as "Exodus probabilities" in this article. Its discovery and utility are illustrated and elaborated with application in COVID-19. This methodology is also useful in applications in engineering, epidemiology, marketing, communication networking, etc.

Conclusion: What is quite novel about the discovery of the exodus probability in this article is the evolution of the concepts from the structural-zero category. In such situation, when a category is eliminated, the proportions of the sample might have uncommunicatively transited to other viable categories and our research question is all about configuring their proportions. This is an innovative approach.

Keywords: public knowledge, perception, communication, sample space, dependent probabilities, Venn layout, odds, odds ratio, survey outcomes

\section{Introduction}

It is quite needless to formally describe the pandemic COVID-19 (otherwise known as coronavirus) ever since January 2020, the whole world is frightened by the viral nature of this pandemic. The symptoms include but are not limited to loss of smell, nasal congestion, body pain, cough, vomiting, sore throat, fever, breathing difficulties, etc. These symptoms change over time. The virus spreads mainly through the respiratory route after an infected person coughs, sneezes, sings, talks or breathes. A new infection occurs when virus-containing particles exhaled by an infected person. To reduce infection, staying at home, wearing a mask in public, avoiding 
crowded places, keeping distance from other, washing hands with soap and water often and for at least 20 seconds, and avoiding touching the eyes, nose, or mouth with unwashed hands are a few preventive practices. The elderly (above the age 65) are in high-risk group to catch Covid-19 virus. For all these preventive measures require supporting working policies by moving some or all work out of the office. For an excellent narration of initial and later periods of the COVID-19 epidemic is given in. ${ }^{2}$

On 24th January 2020 in the Wuhan city (capital of the Hubei province), China, an unknown virus was noticed (Cohen, 2020). China reported to have seen 1287 coronavirus cases and 41 among them have died. ${ }^{19}$ The reader is referred to $^{13}$ for an exposure of the virality of the COVID-19 so far as its human-to-human transmission. Quickly, the nation informed the World Health Organization (WHO). The WHO decided to name it COVID-19 to the deadly virus and warned all nations on earth about its pandemic virality. In the initial phase, health professionals misunderstood that the virus was non-communicable among humans but was deadly only to animals. ${ }^{13}$ This misunderstanding happened to be quite disastrous to the world community. The reader is referred to the following link to clear the misunderstanding: https://www.researchgate.net/publication/340569667, DOI: 10.31124/advance. 12102816.v1.

On 25th March w020, a shocking surprise was felt by China after noticing an estimated 81, 285 persons were inflicted by COVID-19 and 3287 among them died without any successful treatment. Frightened by this quick high number of deaths, several nations warned their citizens not to travel, quarantined the diagnosed COVID-19 cases in their home or emergency shelters. Also, the nations advised the citizens to maintain social distancing and practice personal hygienic precautions as the COVID19's incubation time ranged from 2 to 14 days between the exposure and onset as the incubation time was guessed (not medically proven). ${ }^{2}$ As of 2 nd March 2021, there have been more than 114,441,348 COVID-19 cases worldwide and at least 2,538,681 deaths have occurred already (https://www.researchgate.net/publication/340569667, DOI: 10.31124/advance. 12102816.v1 for more detail). The numbers are wobbling and revamping daily. The seriousness of the health hazards and the terror of mortality cannot be overstated. The daily norms of life were crippled. The enjoyment, creativity, personal and national growth reached near zero everywhere on earth. The reader is referred to ${ }^{19}$ about the initial symptoms of the COVID19 and one of them is pneumonia-type feeling. The pandemics called COVID-19 has been terrorizing and killing people. The patterns were unsolvable challenges to researchers, healthcare and medical practitioners and much more so to the governing agencies.

Many surveys have been conducted internationally (like the one by ${ }^{6}$ to capture the facts and fears among the public). Because some of the questions were worded in such a way, they created what is called structural-zero (different from the sampling zero) category with respect to the perception, knowledge, and communication about the COVID-19 pandemics by the respondents of surveys. A research question that can be posed is that there might have been a proportion in the disappeared category if the written questions were to be not mutually exclusive, but it did not happen. Such missing proportions in the survey due to the mutually exclusive questions ought to have migrated to other viable categories. Is there a method to appraise the proportions who might have transited from the fourth (structurally zero) category to other three tenable categories? This question is answered in an innovative modus operandi in this article using a recent survey data on COVID-19.

\section{Public Communication, Knowledge, and Perception}

A survey ${ }^{6}$ was performed on the pandemic COVID-19 among the Malaysians to examine their public perception, knowledge, and scientific communication of its virality. The public knowledge is often connected with the risk to survive. The perception is based on more of cultural or gender bias. The Science communication is a skill due to education to effectively disseminate information in the public domain. A follow-up article by ${ }^{7}$ also raised the awareness of possible epidemic trajectories (due to the COVID-19's second wave). The awareness is a necessity after the Malaysia's Movement Control Ordinance (MCO) was lifted. During 24th January to 21st February 2020, in Malaysia, the first wave of COVID-19 occurred. The second wave began on 27 February 2020. The Malaysian government announced an $\mathrm{MCO}$, which had been extended already three times by two weeks each time. This article (PMID 32617314) discusses the trajectory in detail about the trajectory in various countries. The reader is referred to ${ }^{1,3,4,8-12,14-17}$ for recent epidemiological and public health developments on collected data, including the Malaysian data that are analyzed and interpreted in this article. 
Table I Survey Data on Malaysians Knowledge About COVID-196

\begin{tabular}{|c|c|c|c|}
\hline Knowledge & A (Agree) & B (Disagree) & $\bar{A} \bar{B}$ (Neither) \\
\hline $\begin{array}{l}\text { COVID- } 19 \text { is a contagious disease that causes symptoms in lungs and airways like coughing, sore } \\
\text { throat and difficulty breathing. (True), } \mathrm{KI}\end{array}$ & 0.989 & 0.008 & 0.003 \\
\hline $\begin{array}{l}\text { COVID- } 19 \text { is caused by a bacterium called SARS-CoV- } 2 \text { and can be treated with antibiotics. } \\
\text { (False), K2 }\end{array}$ & 0.171 & 0.182 & 0.647 \\
\hline $\begin{array}{l}\text { COVID- } 19 \text { is a disease caused by a virus that previously only infected animals but now infects } \\
\text { humans. (True), } \mathrm{K} 3\end{array}$ & 0.702 & 0.141 & 0.157 \\
\hline $\begin{array}{l}\text { COVID- } 19 \text { is a pandemic disease which means it was not making people sick previously, but now } \\
\text { has spread all over the world. (True), K4 }\end{array}$ & 0.685 & 0.121 & 0.194 \\
\hline There is currently no approved vaccine to prevent COVID-19. (True), K5 & 0.935 & 0.040 & 0.025 \\
\hline
\end{tabular}

The outcome of their online anonymous survey is summarized in Table 1 through 3. It is these data that provided basic motivation to prepare this article. In the survey, there were five, six, eight questions posed to the respondents in knowledge, perception, and communication categories. For each question, a respondent answer either $(A)$ agree, $(B)$ disagree, or $(\bar{A} \bar{B})$ neither. Notice that the possibility for $(A B)$ is void. Consequently, the option $(A B)$ is nullified and became a structurally zero category. The reader is referred to ${ }^{5}$ for more detail on structural zero. The structural zero category arises in a situation in which it is impossible to have a response. The literature distinguishes the difference between the structural zero and sampling zero scenarios ${ }^{5}$, for details]. In other words, a proportion in this structurally zero category ought to have transited to one of other three categories: $(A)$ agree, $(B)$ disagree, or $(\bar{A} \bar{B})$ neither. What are such percentages who might have done the exodus from the structural zero category to the three tenable categories?

\section{Methods}

\section{Exodus Probabilities: New Probability Expressions}

In conjunction with the stated research aim in the previous section, let the sample space consists of three mutually exclusive possible categories: $S=\{A, B, \bar{A} \cap \bar{B}\}$ in the Venn diagram. See ${ }^{18}$ for the definition and properties of the Venn diagram. An answer to any (knowledge, perception, or communication) question is associated with the options of selecting only anyone of the three mutually exclusive categories since $\operatorname{Pr}(A B)=0$ by the default of structural zero. In other words, $\operatorname{Pr}(S)=1$. Also, $1-\operatorname{Pr}(A \cup B)=\operatorname{Pr}(\bar{A} \cap \bar{B})=1-\operatorname{Pr}(A)-\operatorname{Pr}(B)$ due to the law by DeMorgan's $\left[{ }^{18}\right.$, for details $]$ and the structural zero fact $\operatorname{Pr}(A \cap B)=0$. The reader is referred to the classic book by ${ }^{18}$ for the fundamental concepts and rules of probability in the interpretations of scientific data. We now introduce a probability type measure in (1)

$$
\frac{\operatorname{Pr}(\bar{A})-\operatorname{Pr}(\bar{A} \cap \bar{B})}{1-\operatorname{Pr}(\bar{A} \cap \bar{B})}=\theta_{\bar{A}}
$$

Because the laws state an intersection probability is less than the marginal probability (that is $1 \geq \operatorname{Pr}(\bar{A}) \geq \operatorname{Pr}(\bar{A} \cap \bar{B}) \geq 0$ ), we notice that $\geq \theta_{\bar{A}} \geq 0$. Hence, we formally define the exodus odds in the definition 1 below to refer the odds of transiting from a structural-zero event.

Definition 1. The exodus odds of transiting from the structurally zero category, $A \cap B$ to the category $\bar{A}$ is

$$
\frac{\operatorname{Pr}(\bar{A})-\operatorname{Pr}(\bar{A} \cap \bar{B})}{1-\operatorname{Pr}(\bar{A})}=\left(\frac{\theta_{\bar{A}}}{1-\theta_{\bar{A}}}\right)
$$

Likewise, we define its complementary exodus odds for transiting from a structurally zero category, $A \cap B$ to the category $\bar{B}$. Analogous expression is

$$
\frac{\operatorname{Pr}(\bar{B})-\operatorname{Pr}(\bar{A} \cap \bar{B})}{1-\operatorname{Pr}(\bar{A} \cap \bar{B})}=\theta_{\bar{B}}
$$

which possesses properties like what exists for (1). By combining both expressions, we notice that

$$
\theta_{\bar{A}}-\frac{\operatorname{Pr}(\bar{A})-\operatorname{Pr}(\bar{B})}{1-\operatorname{Pr}(\bar{A} \cap \bar{B})}=\theta_{\bar{B}}
$$

where

$$
\operatorname{Pr}(\bar{A} \cap \bar{B})=\frac{\operatorname{Pr}(\bar{B})-\theta_{\bar{B}}}{1-\theta_{\bar{B}}}=\frac{\operatorname{Pr}(\bar{A})-\theta_{\bar{A}}}{1-\theta_{\bar{A}}}
$$

is a proportionality statement and it yields an imbalance measure between the events $\bar{A}$ and $\bar{B}$ 


$$
\Delta=-\left\{\theta_{A}+\left(1-\theta_{\bar{A}}\right) \operatorname{Pr}(\bar{B})\right\}+\left\{\theta_{\bar{B}}+\left(1-\theta_{\bar{B}}\right) \operatorname{Pr}(\bar{A})\right\}
$$

We name $\theta_{\bar{A}}$ and $\theta_{\bar{B}}$ the exodus probability to $A$ and $B$ respectively. In conjunction with the exodus probabilities, realize that

$$
\begin{aligned}
P(\bar{A} \cap \bar{B}) & =1-P(A)-P(B) P(A \cap \bar{B})=P(A) \\
& =1-P(\bar{A}), 1-P(\bar{B})=P(\bar{A} \cap B)=P(B)
\end{aligned}
$$

because

$$
P(A \cap B)=P(\text { empty })=0
$$

Furthermore, we notice from (1) that $\frac{\operatorname{Pr}(\bar{A})-\theta_{\bar{A}}}{1-\theta_{\bar{A}}}=\operatorname{Pr}(\bar{A} \cap \bar{B})$ implying that $\left(1-\theta_{\bar{A}}\right) \operatorname{Pr}(\bar{B} \mid \bar{A})+\frac{\theta_{\bar{A}}}{\operatorname{Pr}(A)}=1$

Consequently, the conditional probability could be written as

$$
\frac{\left[\operatorname{Pr}(\bar{A})-\theta_{\bar{A}}\right]}{\left[1-\theta_{\bar{A}}\right] \operatorname{Pr}(\bar{A})}=\operatorname{Pr}(\bar{B} \mid \bar{A})
$$

What is known is that the unconditional probability is lesser than the conditional probability. That is, $\operatorname{Pr}(\bar{B}) \leq \operatorname{Pr}(\bar{B} \mid \bar{A})$. Hence, we can assess how much an impact of knowing that $\bar{A}$ has occurred on speculating the likelihood of $\bar{B}$ and such an impact is

$$
\begin{aligned}
& \frac{\{\operatorname{Pr}(\bar{A})-\operatorname{Pr}(\bar{A} \cap \bar{B})\}-\theta_{\bar{A}}\{1-\operatorname{Pr}(\bar{A} \cap \bar{B})\}}{\left(1-\theta_{\bar{A}}\right) \operatorname{Pr}(\bar{A})}=\delta_{\bar{A} \rightarrow \bar{B}} \\
& \quad=\operatorname{Pr}(\bar{B} \mid \bar{A})-P(\bar{B})
\end{aligned}
$$

An analogous expression to quantify the impact of knowing that $\bar{B}$ has occurred on speculating the likelihood of $\bar{A}$ and such an impact is

$$
\begin{aligned}
& \frac{\{\operatorname{Pr}(\bar{B})-\operatorname{Pr}(\bar{A} \cap \bar{B})\}-\theta_{\bar{B}}\{1-\operatorname{Pr}(\bar{A} \cap \bar{B})\}}{\left(1-\theta_{\bar{B}}\right) \operatorname{Pr}(\bar{B})}=\delta_{\bar{B} \rightarrow \bar{A}} \\
& \quad=\operatorname{Pr}(\bar{A} \mid \bar{B})-P(\bar{A})
\end{aligned}
$$

Definition 2. The transiting exodus odds from the structurally zero category, $A \cap B$ to the category, $\bar{B}$ is

$$
\frac{\operatorname{Pr}(\bar{B})-\operatorname{Pr}(\bar{A} \cap \bar{B})}{1-\operatorname{Pr}(\bar{B})}=\left(\frac{\theta_{\bar{B}}}{1-\theta_{\bar{B}}}\right)
$$

We now could define the exodus odds ratio of transiting from the structurally zero category, $A \cap B$ is then

$$
\begin{aligned}
\left\{\frac{\operatorname{Pr}(B)}{\operatorname{Pr}(A)}\right\}\left\{\frac{\operatorname{Pr}(\bar{A})-\operatorname{Pr}(\bar{A} \cap \bar{B})}{\operatorname{Pr}(\bar{B})-\operatorname{Pr}(\bar{A} \cap \bar{B})}\right\} & =\text { Odds_Ratio } \overline{\bar{A} / \bar{B}} \\
& =\left(\frac{\theta_{\bar{A}}\left[1-\theta_{\bar{B}}\right]}{\theta_{\bar{B}}\left[1-\theta_{\bar{A}}\right]}\right)
\end{aligned}
$$

When the odds ratio, Odds_Ratio $\bar{A}_{\bar{A} / \bar{B}}$ is more than one, the exodus odds to the category,

$\bar{A}$ is more likely than its counterpart category, $\bar{B}$ from the structurally zero category, $A \cap B$.

\section{Illustration with Malaysian Survey Data About COVID-19}

We now illustrate the derived expressions of Section 2 using the survey data about the Malaysians' perception, public knowledge, and scientific communication on the COVID-19. See Tables 1-3 for the observed proportions in each category given in. ${ }^{6}$ There were five, six, and eight questions in the survey covering the respondents' perception, knowledge, and communication about the COVID19. Some of the questions are true and others are false. The truth or falseness of the questions were not revealed to the respondents. The entries in the table are the proportions who agree (disagree) with the question. The events $A$ and $B$ denote respectively the agreement and disagreement by the respondents.

The simultaneous occurrence of the event $A \cap B$ is therefore nullified and hence, the category $A \cap B$ is structurally zero category. The proportion that would have been in the category $A \cap B$ if the category were to be not structurally zero type ought to have migrated to $A, B$, or $\bar{A} \cap \bar{B}$ category. What are such exodus proportions in their transit? That is what explained in this section. For this purpose, the expressions (1) through (7) are computed and stated in the Tables 4-6 below for the Malaysians' knowledge, perception, and communication, respectively.

In Table 4 through 6 , we notice that $\theta_{\bar{A}}$ in (1) is negligible in almost all knowledge, perception, and communication questions but is significantly high only in the false knowledge question, COVID-19 is caused by a bacteria called SARS-CoV-2 and can be treated with antibiotics (K2) and in the communication question, I do not understand details about COVID-19 because they are too technical and complicated (C3).

On the contrary, in Table 4 through 6 , we notice that $\theta_{\bar{B}}$ in (2) is moderate only in false question. The COVID-19 is caused by a bacteria called SARS-CoV-2 and can be treated with antibiotics (K2) and true question: I do not understand details about COVID-19 because they are too technical and complicated (C3) but is quite high in other all perception, knowledge, and communication questions of COVID-19. 
Table 2 Survey Data on Malaysians Perception About COVID-196

\begin{tabular}{|l|l|l|l|}
\hline Perception & A (Agree) & B (Disagree) & $\bar{A} \bar{B}($ Neither) \\
\hline I believe COVID-19 is a very deadly disease, PI & 0.790 & 0.116 & 0.094 \\
I am worried about me and my loved ones getting sick with COVID-19, P2 & 0.963 & 0.028 & 0.009 \\
I am worried about spreading COVID-19 to others, P3 & 0.944 & 0.036 & 0.020 \\
I am worried about the impact of COVID-19 on my work, livelihood and the economy, P4 & 0.96 I & 0.027 & 0.012 \\
I am able to reduce my risk of getting COVID-19 by avoiding crowded public areas, keeping my & 0.99 I & 0.005 & 0.004 \\
hands clean, and not touching my face, P5 & & 0.086 & 0.750 \\
The closures of areas of congregations such as schools and places of worship are an extreme and & 0.164 & & \\
unnecessary measure to control the spread of COVID-19, P6 & & \\
\hline
\end{tabular}

Table 3 Data on Malaysians Communication About COVID-19*6

\begin{tabular}{|c|c|c|c|}
\hline Communication & A (Agree) & B (Disagree) & $\begin{array}{l}\bar{A} \bar{B} \\
\text { (Neither) }\end{array}$ \\
\hline $\begin{array}{l}\text { I obtain most of my information on COVID-I } 9 \text { from friends, family and social groups on social media } \\
\text { (WhatsApp, Facebook, IG, Twitter, TikTok), C2 }\end{array}$ & 0.668 & 0.151 & 0.181 \\
\hline I do not understand details about COVID-I9 because they are too technical and complicated, C3 & 0.116 & 0.209 & 0.675 \\
\hline $\begin{array}{l}\text { I am more likely to understand and prefer to receive info about COVID-I9 on video rather than } \\
\text { articles or static visuals/infographics, C4 }\end{array}$ & 0.430 & 0.335 & 0.235 \\
\hline I have received a lot of quality information on COVID-I9 on social media, C5 & 0.773 & 0.149 & 0.078 \\
\hline I have received a lot of questionable information/fake news on COVID-19 on social media, C6 & 0.779 & 0.139 & 0.082 \\
\hline I am eager to share information that I think can help us reduce the risk and spread of COVID-I9, C7 & 0.798 & 0.152 & 0.050 \\
\hline $\begin{array}{l}\text { I check information I receive on social media with sources such as health andgovernment agency } \\
\text { websites and science news outlets before sharing/forwarding to others, C8 }\end{array}$ & 0.879 & 0.098 & 0.023 \\
\hline $\begin{array}{l}\text { The communication I have received about COVID-I } 9 \text { has strongly influenced how I think about the } \\
\text { disease and what I do to protect myself, my loved ones, and my community, C9 }\end{array}$ & 0.945 & 0.047 & 0.008 \\
\hline
\end{tabular}

Note: *For some reason, the item $\mathrm{Cl}$ is not reported in. Adapted from Mohd Hanafiah, Khayriyyah; Wan, Chang Da (2020): Public knowledge, perception and communication behavior surrounding COVID-19 in Malaysia. Advance. Preprint. https://creativecommons.org/licenses/by/4.0/. ${ }^{6}$

Table 4 Exodus Probabilities for Knowledge on COVID-19

\begin{tabular}{|l|l|l|l|l|l|}
\hline Question & $\begin{array}{l}\theta_{\bar{A}} \text { in } \\
\text { (1) }\end{array}$ & $\begin{array}{l}\theta_{\bar{B}} \text { in } \\
\mathbf{( 2 )}\end{array}$ & $\begin{array}{l}\delta_{\bar{A} \rightarrow \bar{B}} \\
\text { in (5) }\end{array}$ & $\begin{array}{l}\delta_{\bar{B} \rightarrow \bar{A}} \text { in } \\
\mathbf{( 6 )}\end{array}$ & $\begin{array}{l}\text { Odds_Ratio } \\
\text { on (7) }\end{array}$ \\
\hline $\mathrm{KI}$ & 0.008 & 0.991 & 0.003 & $\mathrm{I} / \mathrm{AE}-14$ & $6.543 \mathrm{E}-05$ \\
$\mathrm{~K} 2$ & 0.515 & 0.484 & -0.168 & $1.3 \mathrm{E}-16$ & 1.132 \\
$\mathrm{~K} 3$ & 0.167 & 0.832 & 0.006 & 0 & 0.040 \\
$\mathrm{~K} 4$ & 0.150 & 0.849 & -0.024 & 0 & 0.031 \\
$\mathrm{~K} 5$ & $0.04 \mathrm{I}$ & 0.958 & 0.011 & $-2.8 \mathrm{E}-15$ & 0.001 \\
\hline
\end{tabular}

All data analytic results in Table 4 through 6 suggest that the impact of knowing $\bar{A}$ on the likelihood of $\bar{B}$ in (5) is negative in the false knowledge question: COVID-19 is caused by a bacteria called SARS-CoV-2 and can be treated with antibiotics (K2) and the true knowledge question: COVID-19 is a pandemic disease which means it was not making people sick previously, but now has spread all over the world (K4), in the
Table 5 Exodus Probabilities for Perception on COVID-19

\begin{tabular}{|l|l|l|l|l|l|}
\hline Question & $\begin{array}{l}\theta_{\bar{A}} \text { in } \\
\mathbf{( 1 )}\end{array}$ & $\begin{array}{l}\theta_{\bar{B}} \text { in } \\
\mathbf{( 2 )}\end{array}$ & $\begin{array}{l}\delta_{\bar{A} \rightarrow \bar{B}} \\
\text { in (5) }\end{array}$ & $\begin{array}{l}\delta_{\bar{B} \rightarrow \bar{A}} \\
\text { in (6) }\end{array}$ & $\begin{array}{l}\text { Odds_Ratio } \\
\text { on (7) }\end{array}$ \\
\hline PI & 0.128 & 0.872 & 0.023 & 0 & 0.021 \\
P2 & 0.028 & 0.972 & 0.015 & $-4 \mathrm{E}-15$ & 0.001 \\
P3 & 0.037 & 0.963 & 0.011 & $3.1 \mathrm{E}-15$ & 0.002 \\
P4 & 0.027 & 0.973 & 0.011 & 0 & 0.001 \\
P5 & 0.005 & 0.995 & 0.001 & 0 & $3 \mathrm{E}-05$ \\
P6 & 0.344 & 0.656 & -0.254 & $1.8 \mathrm{E}-16$ & 0.275 \\
\hline
\end{tabular}


Table 6 Exodus Probabilities for Communication on COVID-19

\begin{tabular}{|l|l|l|l|l|l|}
\hline Question & $\begin{array}{l}\theta_{\bar{A}} \text { in } \\
\mathbf{( 1 )}\end{array}$ & $\begin{array}{l}\theta_{\bar{B}} \text { in } \\
\mathbf{( 2 )}\end{array}$ & $\begin{array}{l}\delta_{\bar{A} \rightarrow \bar{B}} \\
\text { in (5) }\end{array}$ & $\begin{array}{l}\delta_{\bar{B} \rightarrow \bar{A}} \text { in } \\
\mathbf{( 6 )}\end{array}$ & $\begin{array}{l}\text { Odds_Ratio } \bar{A}_{\bar{A} / \bar{B}} \\
\text { on (7) }\end{array}$ \\
\hline $\mathrm{C} 2$ & 0.184 & 0.816 & 0.002 & $-7.1 \mathrm{E}-16$ & $0.05 \mathrm{I}$ \\
$\mathrm{C} 3$ & 0.643 & 0.357 & -0.065 & 0 & 3.246 \\
$\mathrm{C} 4$ & 0.438 & 0.562 & 0.277 & $-1.9 \mathrm{E}-16$ & 0.606 \\
$\mathrm{C} 5$ & 0.162 & 0.838 & 0.071 & 0 & 0.037 \\
C6 & $0.15 \mathrm{I}$ & 0.849 & 0.056 & 0 & 0.031 \\
C7 & 0.160 & 0.840 & 0.103 & $-8.2 \mathrm{E}-16$ & 0.036 \\
C8 & 0.100 & 0.900 & 0.071 & $1.23 \mathrm{E}-15$ & 0.012 \\
C9 & 0.047 & 0.953 & 0.035 & $-2.5 \mathrm{E}-15$ & 0.002 \\
\hline
\end{tabular}

Interestingly, the impact of knowing $\bar{B}$ on the likelihood of $\bar{A}$ in (6) is negligible, consistently in all questions of knowledge, perception, and communicative categories. The exodus odds ratio in (7) of transiting from the structural event $A \cap B$ is only in false knowledge question: COVID-19 is caused by a bacterium called SARS-CoV-2 and can be treated with antibiotics (K2) and in the true communication question: I do not understand details about COVID-19 because they are too technical and complicated (C3). For all other questions in knowledge, perception, and communication categories, the exodus odds ratio is less than one. The exodus odds to the event $\bar{A}$ is more likely than its counterpart exodus odds to the event $\bar{B}$ from the structurally zero category, $A \cap B$.

\section{Discussion}

This research article has introduced new concepts called exodus probabilities from a structural-zero category. The structural zero is unavoidable if the surveys consist of two mutually exclusive questions or options. For such a scenario, this article derived new probability expressions (not seen in the journals or books so far). With the availability of the new expressions in this article, we have successfully interpreted and sorted out how the Malaysians have felt about the COVIDS-19 in a recent survey. A respondent could not be counted in both places.

\section{Recommendations for Future Research Work}

The intent and purpose of data collection is to find out the underlying model for the collected data, and the interpretation of data analysis results of COVID-19 is to understand/capture the trend of this pandemic and be prepared to prevent its future occurrence of the pandemic. What else is more important now in year 2020 than finding more correct way to model and understand the COVID-19 data? Imagine if you, us, or someone we know got unfortunately COVID-19 virus, but there is no scientific knowledge about COVID-19, even when they have collected data but have no idea what the data do really mean. This manuscript adds relevant knowledge. This is not true. We mentioned the sample size, how the data are collected in the paper. The lab science research leads to needed vaccination to control COVID-19. Our work is all medical modelling and data analysis. In this article, we echo an opinion that modelling and/or data analysis is quite helpful and valuable in the pursuit of prevention or control COVID-19.

\section{Abbreviations}

COVID-19, Coronavirus disease 2019; MCO, Movement control order; SARS-CoV-2, Severe acute respiratory syndrome coronavirus 2; WHO, World Health Organization.

\section{Data Sharing Statement}

No issue here. The data came from a public domain.

\section{Consent to Participate and Ethics Approval}

No consent and no ethical approval are required to participate since the used data came from a public domain.

\section{Consent for Publication}

Yes, we approve.

\section{Acknowledgments}

The authors thank their universities for supporting this research.

\section{Author Contributions}

All authors made a significant contribution to the work reported, whether that is in the conception, study design, execution, acquisition of data, analysis and interpretation, or in all these areas; took part in drafting, revising or critically reviewing the article; gave final approval of the version to be published; have agreed on the journal to which the article has been submitted; and agree to be accountable for all aspects of the work.

\section{Funding}

No funding is involved. 


\section{Disclosure}

The authors report no conflicts of interest in this work.

\section{References}

1. Altahir AA, Mathur N, Thiruchelvam L, et al. Modeling the impact of lock-down on COVID-19 spread in Malaysia. bioRxiv. 2020.

2. Backer JA, Klinkenberg D, Wallinga $\mathrm{J}$, et al. Incubation period of 2019 novel COVID-19 (2019 nCoV), infections among travelers from Wuhan, China, 20-28 January 2020. Euro Surveill. 2020;25 (5):1-10. doi:10.2807/1560-7917.ES.2020.25.5.2000062

3. Bekele F, Sheleme T, Fekadu G, Bekele K. Patterns and associated factors of COVID-19 knowledge, attitude, and practice among general population and health care workers: a systematic review. SAGE Open Med. 2020;8:2050312120970721. doi:10.1177/2050312120970721

4. Das SS, Tiwari AK. Understanding international and domestic travel intention of Indian travelers during COVID-19 using a Bayesian approach. Tour Recreat Res. 2020;1-17. doi:10.1080/ 02508281.2020 .1830341

5. Gupta RC, Tian S. Statistical inference for the risk ratio in $2 \times 2$ binomial trials with structural zero. Comput Stat Data Anal. 2007;51(6):3070-3084. doi:10.1016/j.csda.2006.02.003

6. Mohd Hanafiah, Khayriyyah; Wan, Chang Da (2020): Public knowledge, perception and communication behavior surrounding COVID19 in Malaysia. Advance. Preprint. https://doi.org/10.31124/advance. 12102816.v1

7. Hanafiah KM, Ayub AJ, Wai GH. Dancing with COVID-19: public health precautions beyond the movement control order. Khazanah Research Institute. Discussion Paper | Dancing with COVID-19, 7/ 20. 30 April 2020.

8. Hartley K, Vu MK. Fighting fake news in the COVID-19 era: policy insights from an equilibrium model. Policy Sci. 2020;53(4):735-758. doi:10.1007/s11077-020-09405-z

9. Hefnawy M, Refat G. Evaluating of the Egyptian knowledge, awareness and applications of infection control strategies toward coronavirus (COVID-19). Int Med J. 2020;27(5). doi:10.31124/advance. 12102816.v1

10. Kabito GG, Alemayehu M, Mekonnen TH, et al. Community's perceived high risk of coronavirus infections during early phase of epidemics are significantly influenced by socio-demographic background, in Gondar City, Northwest Ethiopia: a cross-sectional-study. PLoS One. 2020;15 (11):e0242654. doi:10.1371/journal.pone.0242654
11. Levkovich I, Shinan-Altman S. The impact of gender on emotional reactions, perceived susceptibility and perceived knowledge about COVID-19 among the Israeli public. Int Health. 2021. doi:10.1093/ inthealth/ihaa101

12. Paudel S, Shrestha P, Karmacharya I, Pathak OK. Knowledge, attitude, and practices (KAP) towards COVID-19 among Nepalese residents during the COVID-19 outbreak: an Online Cross-Sectional Study. 2020.

13. Phan LT, Nguyen TV, Luong QC. Importation and human-to-human transmission of a novel COVID-19 in Vietnam. $N$ Engl $\mathrm{J}$ Med. 2020;382(9):872-874. doi:10.1056/NEJMc2001272

14. Rothmund T, Farkhari F, Azevedo F, Ziemer CT. Scientific trust, risk assessment, and conspiracy beliefs about COVID-19-four patterns of consensus and disagreement between scientific experts and the German public. 2020.

15. Saefi M, Fauzi A, Kristiana E, et al. Survey data of COVID-19related knowledge, attitude, and practices among Indonesian undergraduate students. Data Brief. 2020;31:105855. doi:10.1016/j. dib.2020.105855

16. Saefi M, Fauzi A, Kristiana E, et al. Validating of knowledge, attitudes, and practices questionnaire for prevention of COVID-19 infections among undergraduate students: a RASCH and factor analysis. Eurasia J Math Sci Tech Educ. 2020;16(12):em1926. doi:10.29333/ejmste/9352

17. Salman A. Knowledge, curiosity, communication channels and panic during COVID-19 movement control order. Int J Media Commun Res. 2021;2(1):01-11. doi:10.25299/ijmcr.v2i1.6205

18. Stuart A, Ord K. Kendall's Advanced Theory of Statistics, Volume 1: Distribution Theory. Oxford, UK: Oxford University Press;2009. ISBN 978-0-534-24312-8.

19. Zhu N, Zhang D, Wang W. A novel COVID-19 from patients with pneumonia in china, 2019. N Engl J Med. 2020;382(8):727-733. doi:10.1056/NEJMoa2001017
Journal of Multidisciplinary Healthcare

\section{Publish your work in this journal}

The Journal of Multidisciplinary Healthcare is an international, peerreviewed open-access journal that aims to represent and publish research in healthcare areas delivered by practitioners of different disciplines. This includes studies and reviews conducted by multidisciplinary teams as well as research which evaluates the results or conduct of such teams or healthcare processes in general. The journal covers a very wide range of areas and welcomes submissions from practitioners at all levels, from all over the world. The manuscript management system is completely online and includes a very quick and fair peer-review system. Visit http://www.dovepress.com/testimonials. php to read real quotes from published authors. 